\title{
IMPLEMENTASI REDUNDANT LINK UNTUK MENGATASI DOWNTIME DENGAN METODE FAILOVER
}

\author{
${ }^{1}$ Whisnumurti Adhiwibowo, ${ }^{2}$ Ahmad Rudi Irawan \\ ${ }^{1,2}$ Fakultas Teknologi Informasi dan Komunikasi - Universitas Semarang \\ 11whisnu@usm.ac.id, ${ }^{2}$ rudy.rezpect91@gmail.com
}

\begin{abstract}
Network failure not only affects performance, but also affects individuals or industries. Network Downtime can occur for many reasons, the most common is cable damage and network configuration. This condition requires a more reliable network that is not susceptible to network interference. One of the most important aspects of ensuring that network is redundancy. The method to get high is to build a backup system that will still work if it happens on the main system. Redundancy with failover can be a solution when downtime occurs on nodes in the network. Failover is a process of transferring connections to an alternative path caused by a system or hardware or network interruption or abnormality. The implementation method used is the PPDIOO method which has the stages Prepare, Plan, Design, Implement, Operate and Optimize. System implementation simulations are made using GNS3 software. This design will result in the merging of two networks from different ISP, using MikroTik routers and The Dude monitoring applications that are very useful for troubleshooting network problems in CV. Cahaya Alam.
\end{abstract}

Keywords: Network failure (downtime), high availability network, redundancy, redundant link, failover.

\section{PENDAHULUAN}

Jaringan komputer merupakan suatu himpunan interkoneksi sejumlah komputer autonomous. Dalam bahasa yang populer dapat jelaskan bahwa jaringan komputer adalah kumpulan beberapa komputer (dan perangkat lain seperti router, switch, dsb) yang saling terhubung satu sama lain melalui media perantara.[1] Media perantara ini bisa berupa media kabel ataupun media tanpa kabel (nirkabel). Informasi berupa data akan mengalir dari satu komputer ke komputer lainnya atau dari satu komputer ke perangkat yang lain, sehingga masing-masing komputer yang terhubung tersebut dapat saling bertukar data atau berbagi perangkat keras.[1][2].

Ketersediaan jaringan yang terjamin sangat dibutuhkan oleh berbagai organisasi demi melindungi berjalannya bisnis dari kerusakan sistem, kehilangan/kerusakan data maupun kesalahan pemrosesan data. Salah satu aspek terpenting dalam menjamin ketersediaan jaringan adalah redundancy.[3][4] Penerapan redundancy dapat dilakukan dengan cara menginstalasi perangkat ataupun jalur secara ganda pada area-area yang diperlukan.

Redundant Link berfungsi untuk menghindari terjadinya kegagalan. Redundant Link merupakan salah satu standar dalam membangun jaringan dengan adanya Redundant Link, anda masih mempunyai kesempatan beristirahat, makan pagi dengan tenang walaupun ada bagian-bagian tertentu dari jaringan yang gagal bekerja. Semua itu karena anda sudah mempersiapkan cadangan (redundant).[3][4][5].

Salah satu aspek terpenting dalam menjamin ketersediaan yang tinggi adalah redundancy. Pendekatan yang biasanya dilakukan untuk mendapatkan ketersediaan yang tinggi adalah membangun sistem backup yang tetap akan berfungsi bila terjadi kegagalan pada sistem utama.. Untuk mencegah kegagalan dibutuhkan metode 
failover. [3][4] [6].

Metode failover digunakan untuk mencegah terjadinya kegagalan akibat peningkatkan jumlah trafik yang terjadi yang disebabkan load dalam melayani jumlah permintaan yang banyak dari pengguna ISP. Ketika terjadi kegagalan fungsi pada salah satu ISP device maka masih ada satu ISP device yang menjadi backup atau penggantinya. [4][7][8][9].

CV. Cahaya Alam merupakan sebuah lembaga yang bergerak dalam bidang pelayanan jasa dan pengadaan barang untuk jaringan dan content telekomunikasi. Di CV Cahaya Alam sangat membutuhkan internet untuk menjalankan pekerjaan, pemeliharaan pelanggan ataupun aktivasi pelanggan baru. Karena dalam pekerjaan tersebut, CV Cahaya Alam itu harus mengakses internet untuk membuka aplikasi web untuk update pekerjaan dari partner kerja, membuka email untuk transaksi dokumen dan juga media sosial seperti WhatsApp Web untuk koordinasi dengan pelanggan ataupun rekan kerjanya. Dan untuk saat ini CV. Cahaya Alam berlangganan internet dengan ISP indihome dan ISP ICON+, tetapi untuk penggunaannya masih terpisah yaitu ISP indihome untuk ruang teknisi dan icon+ untuk ruang admin. Jika terjadi kegagalan link pada salah satu ISP maka terjadi downtime yang dapat mengakibatkan kerugian untuk perusahaan, karena saat internet mati tidak ada link backup [2][3][4][7]

\section{METODOLOGI}

Dalam penelitian ini peneliti menggunakan model perancangan jaringan PPDIOO dengan 6 fase: Prepare (persiapan), Plan (Perencanaan), Design (Desain), Implement (Implementasi), Operate (Operasi) dan Optimize (Optimasi). [2]

Metode perancangan jaringan PPDIOO yang digunakan dapat digambarkan pada Gambar 1.

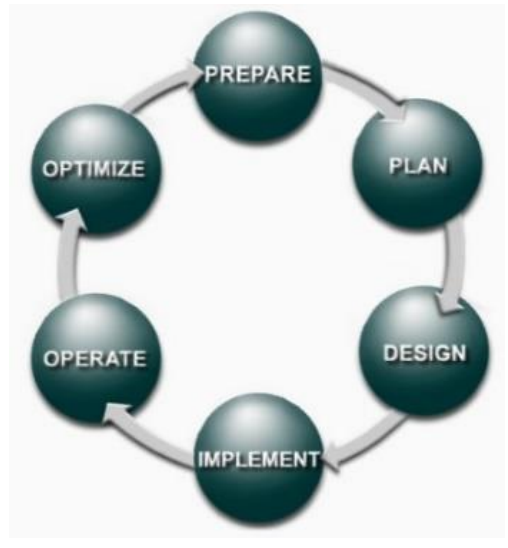

Gambar 1. Model PPDIOO [6]

Metode perancangan jaringan PPDIOO yang terdapat pada Gambar 1, merupakan metode yang digunakan pada penelitian ini. Metode perancangan jaringan PPDIOO mempunyai fase sebagai berikut:

\section{a. Fase Prepare}

Menetapkan kebutuhan apa saja yang dibutuhkan oleh CV. Cahaya Alam dalam mengembangkan jaringan, dan mengusulkan konsep arsitektur yang dibutuhkan yang disesuaikan dengan kemampuan finansial pada perusahaan tersebut.

\section{b. Fase Plan}

Merancang konsep kebutuhan jaringan berdasarkan kepentingan dan kebutuhan pengguna. Fase ini mendeskripsikan karakteristik kebutuhan jaringan, yang memiliki tujuan untuk menilai gap analisis pada perancangan pada sebuah arsitektur.

\section{c. Fase Design}

Desain jaringan dikembangkan berdasarkan persyaratan teknis, dan persiapan yang diperoleh dari kondisi sebelumnya. Hasil desain termasuk didalamnya flow jaringan, dan daftar peralatan jaringan.

\section{d. Implement (Implementasi)}

Perangkat-perangkat

akan disesuaikan dengan yang ada di CV. Cahaya Alam. Setiap langkah dalam implementasi, akan menyertakan deskripsi, perkiraan waktu untuk penerapan, evaluasi, dan informasi lainnya sebagai referensi tambahan. Setelah di lakukan implementasi, dalam fase ini juga dilakukan pengujian 
untuk memastikan bahwa sistem telah berjalan.

\section{e. Operate (Operasi)}

Memastikan jaringan baru yang sudah terimplentasi di CV. Cahaya Alam telah beroperasi dengan normal. Pengelolaan jaringan, pemeliharaan routing, dan mengelola kinerja. Tahapan ini akan dipantau untuk stabilitas dan kinerja jaringan, koreksi konfigurasi, dan kegiatan pemantauan kinerja,

\section{f. Optimize (Optimasi)}

Fase optimasi, memungkinkan untuk memodifikasi desain jaringan, jika terlalu banyak masalah jaringan yang ditimbulkan, dan untuk memperbaiki masalah kinerja,

\section{HASIL DAN PEMBAHASAN}

\section{Sistem Jaringan Yang Sudah Ada}

Sistem jaringan yang sudah ada di gedung admin CV. Cahaya Alam terdapat pada Gambar 2.

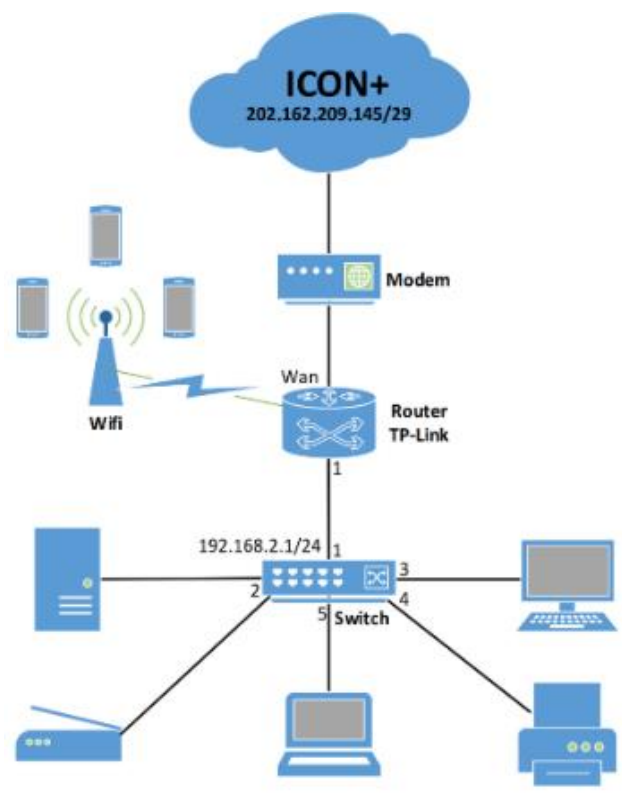

Gambar 2. Sistem Jaringan Gedung Admin

Sistem jaringan yang sudah ada di gedung admin pada Gambar 2, terlihat bahwa jaringan memakai ISP ICON+ sebagai jalur koneksi internetnya dan belum ada jalur lain sebagai link backup.

Sistem jaringan yang sudah ada di gedung teknisi $\mathrm{CV}$. Cahaya Alam terdapat pada Gambar 3.

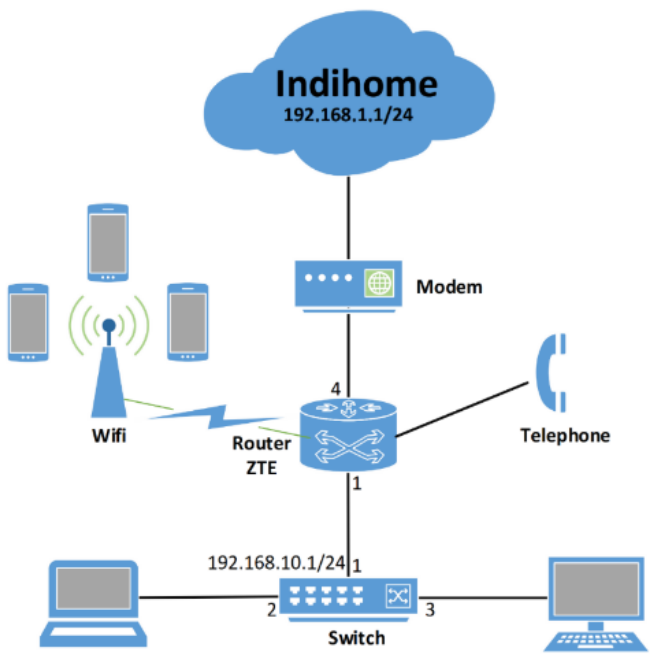

Gambar 3. Sistem Jaringan Gedung Teknisi

Sistem jaringan yang sudah ada di gedung teknisi pada Gambar 3, terlihat bahwa jaringan memakai ISP Indihome sebagai jalur koneksi internetnya dan belum ada jalur lain sebagai link backup.

\section{Desain Topologi}

Desain topologi yang dibangun dapat dilihat pada Gambar 4.

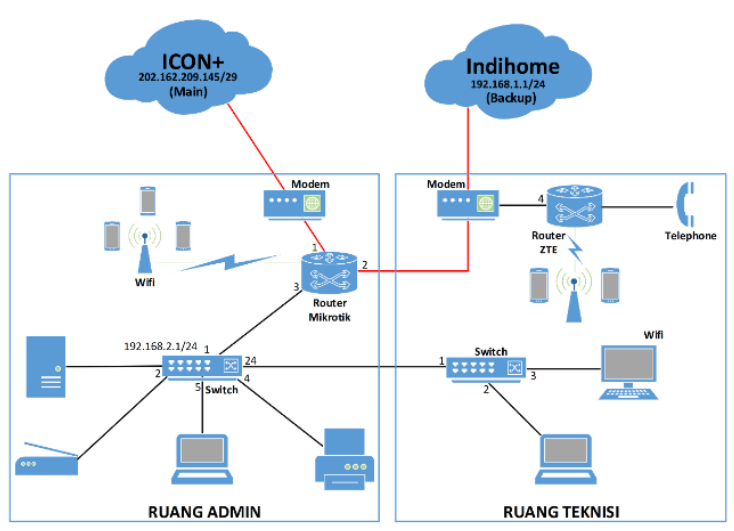

Gambar 4. Desain Topologi

Desain topologi yang dibangun pada Gambar 4, menjelaskan bahwa dilakukan desain topologi penggabungan 2 jaringan yang sudah ada pada gedung admin dan gedung teknisi dengan menggunakan 1 router Mikrotik. Dengan menggunakan ISP ICON+ sebagai primary link dan ISP Indihome sebagai backup link.

\section{Skenario Pengalamatan}

Skenario dari pengalamatan yang diterapkan pada jaringan dapat dilihat pada Tabel 1. 
Tabel 1. Skenario Pengalamatan

\begin{tabular}{|c|c|c|c|}
\hline No. & IP Address & Alokasi Link & Interface \\
\hline $\mathbf{1}$ & $202.162 .209 .146 / 29$ & Primary Link & Ethernet 1 \\
\hline $\mathbf{2}$ & $192.168 .1 .143 / 24$ & Backup Link & Ethernet 2 \\
\hline $\mathbf{3}$ & $192.168 .2 .1 / 24$ & Client & Ethernet 3 \\
\hline $\mathbf{4}$ & $192.168 .3 .1 / 24$ & Wifi & Wlan \\
\hline
\end{tabular}

Skenario pengalamatan jaringan di CV. Cahaya Alam yang diterapkan terdapat pada Tabel 1, menjelaskan bahwa IP Public dari ISP ICON+ yang akan digunakan sebagai primary link di tambahkan pada Ethernet 1. IP Public dari ISP Indihome yang akan digunakan sebagai backup link ditambahkan pada Ethernet 2. IP Address yang akan digunakan client ditambahkan pada Ethernet 3 dan untuk IP Address akses wifi client ditambahkan pada interface wlan pada jaringan.

\section{Konfigurasi Router}

Konfigurasi router dilakukan dengan menggunakan terminal pada Winbox terdapat pada Tabel 2.

Tabel 2. Konfigurasi Router

\begin{tabular}{|c|c|c|c|}
\hline Perangkat & \multicolumn{3}{|c|}{ Konfigurasi } \\
\hline \multirow{14}{*}{$\begin{array}{c}\text { router } \\
\text { MikroTik } \\
\text { RB951Ui- } \\
\text { 2HND }\end{array}$} & system identity & set name & CAHAYAALAM \\
\hline & \multirow[t]{3}{*}{ ip address } & add address & $202.162 .209 .146 / 29$ \\
\hline & & network & 202.162 .209 .144 \\
\hline & & interface & ether1 \\
\hline & \multirow[t]{3}{*}{ ip address } & add address & $192.168 .1 .143 / 24$ \\
\hline & & network & 192.168 .1 .0 \\
\hline & & interface & ether2 \\
\hline & \multirow[t]{3}{*}{ ip address } & add address & $192.168 .2 .1 / 24$ \\
\hline & & network & 192.168 .2 .0 \\
\hline & & interface & ether3 \\
\hline & \multirow[t]{4}{*}{ ip address } & add address & $192.168 .3 .1 / 24$ \\
\hline & & network & 192.168 .3 .0 \\
\hline & & interface & wlan1 \\
\hline & & print & \\
\hline & \multirow[t]{3}{*}{ ip dns } & set server & $202.162 .220 .110,8.8 .8 .8$ \\
\hline & & $\begin{array}{l}\text { allow-remote- } \\
\text { request }\end{array}$ & yes \\
\hline & & print & \\
\hline & \multirow[t]{2}{*}{ ip pool } & add name & To-HUB \\
\hline & & range & $\begin{array}{l}192.168 .2 .2- \\
192.168 .2 .254\end{array}$ \\
\hline & \multirow[t]{2}{*}{ ip pool } & add name & Wifi \\
\hline & & range & $\begin{array}{l}192.168 .3 .2- \\
192.168 .3 .254\end{array}$ \\
\hline & \multirow[t]{5}{*}{ ip dhcp-server } & add name & DHCP HUB \\
\hline & & interface & ether3 \\
\hline & & lease-time & $3 \mathrm{~d} 00: 00: 00$ \\
\hline & & address-pool & To-HUB \\
\hline & & $\begin{array}{l}\text { enable dhcp- } \\
\text { server }\end{array}$ & \\
\hline
\end{tabular}

\begin{tabular}{|c|c|c|}
\hline \multirow[t]{6}{*}{ ip dhcp-server } & add name & DHCP WIFI \\
\hline & interface & wlan1 \\
\hline & lease-time & $3 \mathrm{~d} 00: 00: 00$ \\
\hline & address-pool & Wifi \\
\hline & $\begin{array}{l}\text { enable dhcp- } \\
\text { server }\end{array}$ & \\
\hline & print & \\
\hline \multirow[t]{3}{*}{ ip firewall nat } & chain & srenat \\
\hline & out-interface & ether1 \\
\hline & action & masquerade \\
\hline \multirow[t]{4}{*}{ ip firewall nat } & chain & srenat \\
\hline & out-interface & ether2 \\
\hline & action & masquerade \\
\hline & print & \\
\hline \multirow[t]{4}{*}{ ip route } & "add dst-address & $0.0 .0 .0 / 0$ \\
\hline & gateway & 202.162 .209 .145 \\
\hline & distance & 1 \\
\hline & check-gateway & ping \\
\hline \multirow[t]{5}{*}{ ip route } & add dst-address & $0.0 .0 .0 / 0$ \\
\hline & gateway & 192.168.1.1 \\
\hline & distance & 2 \\
\hline & check-gateway & ping \\
\hline & print & \\
\hline \multirow[t]{2}{*}{ interface } & set & ether1 \\
\hline & name & ICON+ \\
\hline \multirow[t]{2}{*}{ interface } & set & ether2 \\
\hline & name & Indihome \\
\hline \multirow[t]{3}{*}{ interface } & set & ether3 \\
\hline & name & HUB \\
\hline & print & \\
\hline
\end{tabular}

Konfigurasi router Mikrotik yang telah dilakukan pada Tabel 2, menjelaskan bahwa konfigurasi IP Address sesuai dengan scenario pengalamatan yang sudah dibuat dan untuk default route dilakukan sebanyak 2 kali, masing masing menggunakan parameter gateway sesuai kedua ISP. Primary link memiliki distance $=1$ yang berarti jalur ini akan lebih diutamakan dibandingkan jalur kedua, memiliki option check gateway yang berarti jalur ini akan terus dipantau oleh router setiap saat sehingga dapat mengetahui bila jalur tersebut mengalami gangguan. Kedua Backup link memiliki distance $=2$ yang berarti jalur ini akan menjadi jalur cadangan (backup link) dan hanya akan digunakan bila primary link mengalami gangguan.

\section{Hasil Konfigurasi Dengan Failover}

Hasil konfigurasi dengan failover pada router dapat dilihat pada Gambar 5. 


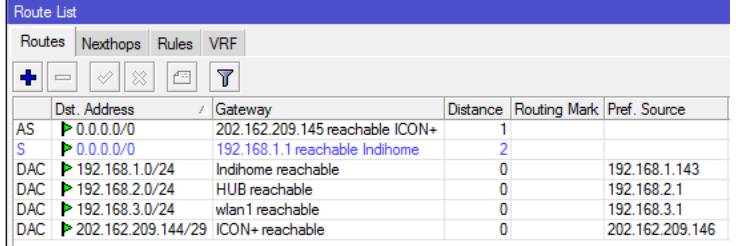

Gambar 5. Hasil Konfigurasi Dengan Failover

Hasil konfigurasi dengan failover pada Gambar 5, terlihat bahwa gateway primary link status aktif dan sedang berjalan dengan distance 1. Kemudian untuk gateway backup link status standbay dengan distance 2 yang siap sebagai link cadangan.

\section{Monitoring Jaringan}

Monitoring jaringan dilakukan untuk memantau aktivitas pada jaringan, agar dapat mengetahui jika ada masalah atau kegagalan pada jaringan yang dimonitoring. Monitoring jaringan redundant link dengan metode failover yang diimplementasikan di CV. Cahaya Alam menggunakan aplikasi The Dude.

\section{Monitoring Jaringan Saat Kondisi Normal} Monitoring jaringan saat kondisi jaringan normal terdapat pada Gambar 6.

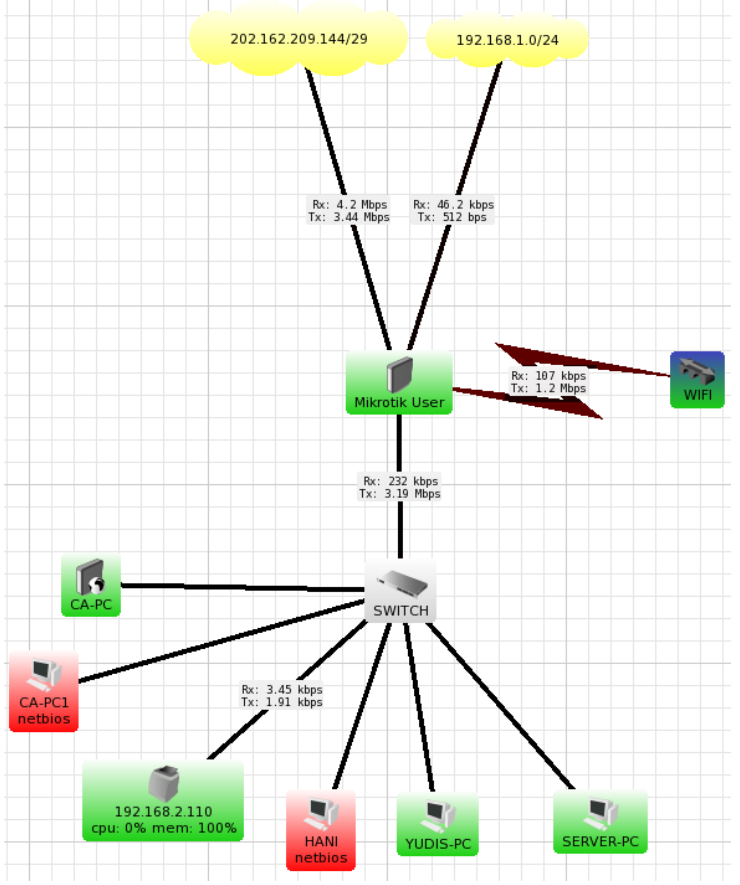

Gambar 6. Monitoring Jaringan Saat Kondisi Normal

Monitoring jaringan saat kondisi normal pada Gambar 6, terlihat bahwa semua device sudah terhubung dengan network ISP ICON+ dan ISP Indihome. Primary link sedang berjalan saat kondisi jaringan normal sedangkan backup link tidak berjalan atau tidak ada aktivitas koneksi karena hanya akan aktif bila primary link mengalami gangguan. Jadi backup link secara otomatis akan menggantikan jalur koneksi dari primary link.

\section{Monitoring Saat Primary Link Putus}

Monitoring jaringan saat kondisi jaringan primary link putus terdapat pada Gambar 7.

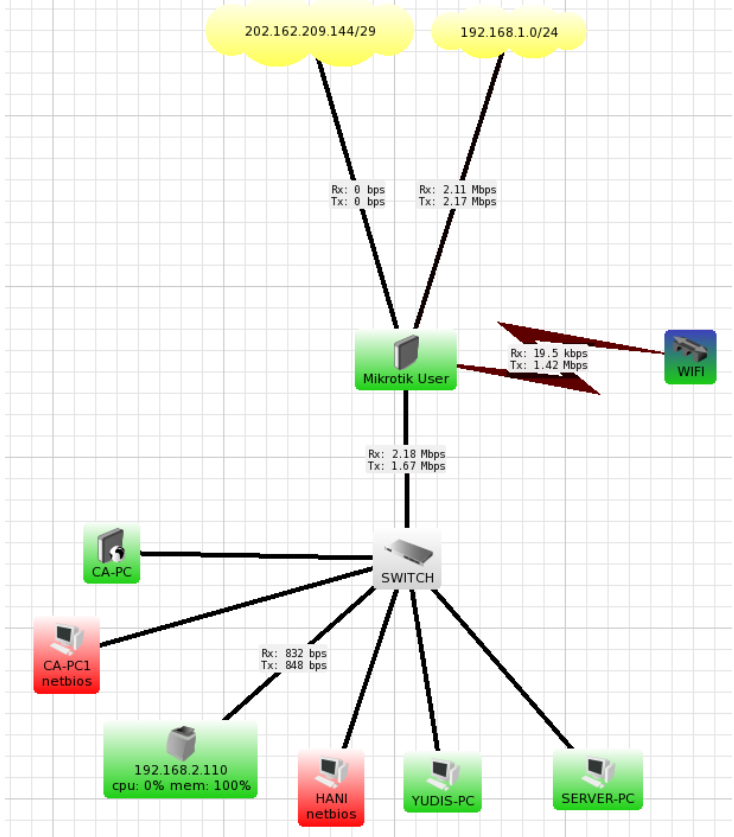

Gambar 7. Monitoring Jaringan Saat Kondisi Primary Link Putus

Monitoring jaringan saat kondisi primary link putus pada Gambar 7, terlihat bahwa koneksi primary link berhenti dan backup link secara otomatis aktif untuk menggantikan koneksi primary link.

\section{KESIMPULAN}

Redundant link dapat diterapkan pada sebuah jaringan untuk membantu mengatasi downtime, meningkatkan keandalan serta ketersediaan jaringan yang terjamin dan failover pada router dapat membantu jaringan bekerja secara otomatis saat salah satu link mengalami kegagalan jaringan.

Agar implementasi redundant link dapat berjalan dengan lancar, proses pembuatan desain jaringan harus dilakukan dengan baik, 
bisa ditambahkan teknik load balancing untuk menghindari overload pada salah satu jalur koneksi dan agar lebih sering dilakukan monitoring jaringan untuk memantau aktivitas koneksi pada jaringan.

\section{DAFTAR PUSTAKA}

[1] Herlambang, moch linto azis. (2008). Panduan Lengkap Menguasai Router Masa Depan menggunakan Mikrotik Router OS. Jogjakarta: Andi

[2] Sofana Iwan, 2013, CISCO CCNA \& Jaringan Komputer ,Bandung, Informatika.

[3] Agni Isador Harsapranata, 2015, Implementasi Fail Over Menggunakan Jaringan Vpn Dan Metronet Pada Astridogroup Indonesia, Jurnal Teknik dan Ilmu Komputer, Vol. 04 No. 13, Jan - Mar 2015

[4] Agni Isador Harsapranata, 2015, Implementasi Failover Menggunakan Jaringan Vpn Dan Metronet Pada Astridogroup Indonesia ,ISSN : 1978 -8282, Vol.8 No.2 Januari 2015

[5] Made Widhi Wirawan, Komang Tris Sumarianta, 2011, Implementasi Load Balance pada jaringan multihoming menggunakan router dengan metode Round Robin, Jurnal Ilmu Komputer, Vol 4 No 1, Universitas Udayana.

[6] Johnson, 2014, Load Balancing and Failover of Gateway Devices, United States: Patent Application Publication.

[7] Kambourakis G., et al. 2010, High Availability for SIP: Solutions and Real-Time Measurement Performance Evaluation, Greece, University of the Aegean.

[8] Rendra Towidjojo, 2012, Konsep \& Implementasi Routing dengan Router Mikrotik 100\% Connected, Jasakom.4.

[9] Moniruzzaman A. B. M, Md. Waliullah, \& Md. Sadekur Rahman, 2015, A High Availability Clusters Model Combined with Load Balancing and Shared Storage Technologies for Web Servers, Bangladesh, Daffodil International University. 